\title{
Fenómeno de Raynaud y el amamantamiento doloroso
}

\author{
Francisco Javier Mirón Muñoz ${ }^{a}$, María Dolores Camacho Martos ${ }^{b}$
}

a Residente de MFyC, Unidad Docente Ciudad Real (Zona I).

b Tutor de Residentes, Unidad Docente Ciudad Real (Zona I).

Correspondencia:

Francisco Javier Mirón Muñoz, c/ Fresno de Cantespino $n^{\circ} 22$ Portal D, Piso $4^{\circ} \mathrm{A}$, 28051- Madrid.

Correo electrónico:

miron60@hotmail.com.

Recibido el 18 de julio de 2011.

Aceptado para su publicación el 28 de agosto de 2011 .

\section{RESUMEN}

El fenómeno de Raynaud es una patología provocada por la exposición al frío, que conduce al vasoespasmo intermitente de arteriolas, produciendo un cuadro clínico por la falta de aporte de oxígeno, consistente en palidez, parestesias y dolor de la zona afectada ${ }^{1}$.

Es una causa tratable de amamantamiento doloroso que llega a afectar a 1 de cada 5 mujeres en edad fértil y que en ocasiones lleva al abandono de la lactancia si es erróneamente diagnosticado por su incomoda sintomatología

Palabras Clave. Enfermedad de Raynaud, Lactancia Materna.

\section{ABSTRACT}

Raynaud's phenomenon and pain during breastfeeding

Raynaud's phenomenon of the nipple is a pathology precipitated by exposure to cold and leads to intermittent vasospasm of arterioles, producing clinical symptoms of pain, burning and paresthesias.

This condition is a treatable cause of painful breastfeeding that can affect up to 1 in 5 women of childbearing age. If misdiagnosed, it can occasionally lead to cessation of breastfeeding due to its uncomfortable symptomatology.

Key words. Raynaud Disease, Breast Feeding.

\section{INTRODUCCIÓN}

Aunque el fenómeno de Raynaud es una patología de sobra conocida y definida en nuestro medio de atención primaria, su localización a nivel del pezón en relación con el amamantamiento doloroso es poco descrita. Su desconocimiento puede llevar a un retraso del diagnóstico y, por lo tanto, puede influir en el abandono de la lactancia por parte de la madre, siendo una patología fácilmente tratable y muy agradecida.

Presentamos un caso de una primípara de 28 años incorrectamente diagnosticada que en realidad presentaba un fenómeno de Raynaud del pezón.

\section{OBSERVACIONES CLÍNICAS}

Se presenta el caso de una mujer de 28 años de edad que acudió a la consulta por primera vez procedente de otra localidad. Diagnosticada de diabetes mellitus 1 sin complicaciones, realizaba tratamiento con insulina. No presentaba otros antecedentes personales de interés.

Refirió que hacía 2 meses había dado a luz un varón de 3.800 gramos de peso mediante parto eutócico sin complicaciones, iniciando la lactancia sin problemas. Sin embargo, a los pocos días presentó dolor en ambas mamas, con predominio en la mama derecha, que empeoraba al amamantar a su hijo. 
Fue tratada de grietas del pezón con antifúngicos y medidas físicas por posible presencia de cándida albicans en sendas ocasiones, no mejorando. Se había fijado en que ambos pezones cambiaban de color, pasando de estar blancos a ponerse azulados al final de la lactancia, sobretodo si el aire acondicionado del centro de trabajo estaba funcionando. Acudió desesperada, planteándose dejar la lactancia.

Se diagnosticó de Raynaud del pezón e iniciamos tratamiento con nifedipino, mejorando rápidamente su cuadro de dolor relacionado con el amamantamiento.

\section{COMENTARIOS}

El fenómeno de Raynaud del pezón fue descrito por primera vez en 1970 en EEUU, afectando al $20 \%$ de las mujeres en edad fértil ${ }^{3}$. Se ha asociado a diversas enfermedades endocrinas y reumatológicas, así como al uso de tóxicos y medicaciones. Se produce por un vasoespasmo de las arteriolas, causando una isquemia intermitente que se manifiesta clínicamente con palidez y cianosis por la caída en el aporte de oxígeno. Tras esto y como fenómeno de rebote, se produce una vasodilatación de la zona, traduciéndose en una rubefacción.

Aunque el vasoespasmo suele estar provocado por la exposición al frío, se han descrito otros precipitantes como el estrés emocional ${ }^{1,3}$. Clínicamente se manifiesta como un dolor agudo intenso y punzante en el pezón, acompañado de cambio de color. Este cambio de coloración suele ser trifásico (blanco, azulado y rojo), aunque en ocasiones puede ser bifásico (de blanco a azul). El dolor empeora con el frío y mejora con el calor, y puede acompañarse de grietas, ampollas o úlceras ${ }^{3}$. Puede asociarse a lesión del tipo de la esclerodermia ${ }^{4}$.

Nuestra labor en Atención Primaria será fundamental para establecer el diagnóstico diferencial, fundamentalmente con grietas en los pezones e infección por cándida albicans. En estas patologías el dolor surge sólo durante y tras las tomas y no se modifica con la temperatura.

El tratamiento ${ }^{2}$ irá encaminado a:

- Prevenir la exposición al frío.

- Amamantar en entorno cálido usando ropa cálida.
- Evitar el uso de drogas y el consumo de cafeína o nicotina.

- Favorecer el ejercicio aeróbico, suplementos de magnesio y calcio, vitamina B6 y aceite de Onagra.

- Aunque los IECAs y lo ISRS son útiles, están contraindicados durante la lactancia.

- De elección: nifedipino.

El nifedipino actúa bloqueando lo canales de calcio, inhibiendo la reabsorción del calcio por las células de la musculatura lisa y favoreciendo su efecto vasodilatador, aliviando rápidamente los síntomas. Es muy seguro en la madre lactante por su escasa eliminación por la leche $(<1-10,3 \mu \mathrm{g} / \mathrm{L})^{5}$. Se prescribe en dosis únicas de $30 \mathrm{mg}$ cada 24 horas durante 2 semanas, pudiendo repetirse un segundo o tercer ciclo si no hubiera sido efectivo el primero

\section{BIBLIOGRAFÍA}

1. Rozman C. Angiología. Arteriopatías funcionales. Síndrome y enfermedad de Raynaud. Compendio de Medicina Interna. $4^{a}$ Ed. Elservier España; 2009. p.194-195.

2. Harrison's Practice. Answer on demand. The McGraw-Hill Company. (Consultado el 12/02/2010). Disponible en: http:// www.harrisonspractice.com/practice/ub/view/Harrisons $\% 20$ Practice/141268/Raynaud's_Phenomenon.

3. Anderson E, Held N, Wright K. Raynaud's phenomenon of the nipple: a treatable cause of painful breastfeeding. (Consultado el 01/02/2011). Pediatrics. 2004; 113:e360. Disponible en: http://pediatrics.aapublications.org/cgi/ reprint/113/e360.pdf.

4. Kirby I, Bland E, Copeland M. Neoplasias epiteliales y enfermedades dermatológicas. La mama: Manejo multidisciplinario de las enfermedades benignas y malignas.

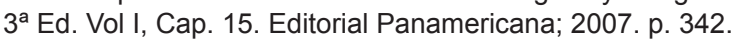

5. Zarpardiel I, De La Fuente J, Bajo JM. Fármacos durante la lactancia. Guía práctica de urgencias en obstetricia y ginecología (Acorde con los protocolos de la S.E.G.O.). Disponible en: http://www.slideshare.net/TARIK022/guiapractica-de-urgencias-en-ginecologia-y-obstetricia-sego-bycriss. 